\section{THE CEREAL BALANCE.}

$A \mathrm{~S}$ the harvest year of $1917-18$ approaches its end the question of the relation between supplies and rate of consumption of bread-corn assumes increased interest and importance. Europe and North America are breaking into their last reserves of home-produced cereals of the $19{ }^{7} 7$ crop. If these prove inadequate to meet requirements from the present time until August next, what is the world reserve available to bridge the gap between the old and the new crop? The reply is given by the International Institute of Agriculture in a valuable analysis of supplies and requirements recently issued. ${ }^{1}$ The analysis covers the agricultural season beginning with August, 1917, and ending with July, 1918, and is based upon returns as to production and estimated consumption of cereals in all important countries where international trade has been maintained, including, therefore, all Entente and neutral countries, but excluding Russia and Roumania.

As regards supplies, the relative yields of cereals in 19I7 (northern hemisphere) and 1917-18 (southern hemisphere) as compared with the previous season $(a)$, and with the average of the three preceding seasons, I9I4-I6 $(b)$, are shown by the following summary :-

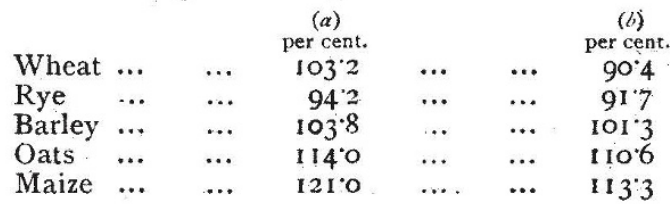

In the aggregate the cereal crops of 1917 show an increase of 223 million quintals over 1916 , or 72 million quintals over the average of the three years 1914-16, the increases being mainly due to last summer's abundant crops of oats and maize in the United States. Wheat alone shows an inerease of 19 million quintals over 1916, and a decrease of $64 \frac{1}{2}$ million quintals as compared with the three-year average.

To these supplies the carry-over from previous crops needs to be added, but very few countries have been able to show any such reserves in excess of the usual carry-over, Australia being the outstanding exception.

When these estimates of supplies are compared with the estimates of requirements up to next harvest supplied to the institute by the various Governments, the following margins of assets over liabilities (in millions of quintals) are shown for the different crops :-

\begin{tabular}{lrr|llc} 
Wheat & $\ldots$ & $44 \frac{1}{2}$ & Oats & $\ldots$ & $62 \frac{1}{2}$ \\
Rye $\ldots$ & $\cdots$ & $2 \frac{1}{2}$ & Maize & $\cdots$ & 157 \\
Barley & $\cdots$ & $12 \frac{1}{2}$ & & &
\end{tabular}

or a total reserve of assets beyond requirements of 279 million quintals. The preponderance of oats and maize in this surplus is a factor to be considered in determining its real value. The light natural weight of the oat grain interferes with transport under conditions of shortage of

1 "Statistical Notes on the Cereals," No. 7, pp. ${ }_{336 .}$ (Rome: Internat. Inst. Agric., xgr 8.)

NO. $254 \mathrm{I}$, VOL. IOI] tonnage, and consequently in many countries the consumption must be limited to the home-growth, within a very small margin. The handsome surplus of maize is the result of the very large crop of the United States, but so far it has unfortunately been most difficult to transport owing to the risk of heating consequent on an abnormally high moisture-content.

Earlier forecasts of the situation suggested the probability of an actual deficit of supplies, and it is all the more welcome, therefore, to find, now that more trustworthy data are available, that so far from this being the case the world, taken as a whole, has ample supplies to meet all its requirements.

The real gravity of the situation lies in the fact that the large reserves are in a few countries, such as Australia, Argentina, British India, and North America, while there is a large deficiency in Europe. Transportation is notoriously surrounded with difficulties owing to the scarcity of tonnage and the enormous rise in rates of ocean freight. The cost of carrying a quarter of wheat from Argentina to Great Britain is twenty times what it was before the war, and other freights have advanced in like manner.

It is clear, therefore, that the disclosure of a substantial world reserve of cereals in no way diminishes the need for the utmost effort to extend cereal production and to economise in cereal consumption in the countries where a deficiency exists and in countries nearest to them. The greater the success of this effort the more effective will the world reserve be in augmenting supplies and reducing prices in the future when a greatly increased tonnage becomes again available for the grain trade.

\section{DR. G. K. GILBERT.}

$\mathrm{O}^{\mathrm{N}}$ May $\mathrm{I}$ a very notable figure passed away from the field of geological discovery and research. Dr. Grove Karl Gilbert was born in Rochester, N.Y., in 1843 , and had thus almost completed his seventy-fifth year. In his "Report on the Geology of the Henry Mountains," issued by the U.S. Geographical and Geological Survey of the Rocky Mountain region in 1877 , he developed the theory of the expansion of intrusive igneous sheets into the great cauldron-like masses that he conveniently styled "laccolites" (stone cisterns), and the rapid recognition of laccolites throughout the world bore witness to the cogency of his exposition. From 1879 onwards he was attached to the staff of the U.S. Geological Survey, and it is not too much to say that his reports helped considerably to direct general scientific attention to the earlier publications of that body. His "Contributions to the History of Lake Bonneville" in I882, and his monograph on "Lake Bonneville" in 1890 , became classics for the treatment of vanished lakes in other areas, and also raised important questions as to crustal yielding under load.

An excellent example of Dr. Gilbert's approach to difficult problems may be found in his study of 